Canadian

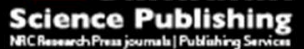

Canadian Journal of Civil Engineering Revue canadienne de génie civil

\title{
Travel demand modeling to simulate traffic loads for pavement deterioration curves: dealing with aggregate data at urban and regional scales
}

\begin{tabular}{|c|c|}
\hline Journal: & Canadian Journal of Civil Engineering \\
\hline Manuscript ID & cjce-2015-0295.R1 \\
\hline Manuscript Type: & Article \\
\hline Date Submitted by the Author: & 25-Aug-2015 \\
\hline Complete List of Authors: & $\begin{array}{l}\text { Amin, Md Shohel; Concordia University, Building, civil \& Environmental } \\
\text { Engineering } \\
\text { Amador-Jiménez, Luis; Concordia University, Building, Civil and } \\
\text { Environmental Engineering }\end{array}$ \\
\hline Keyword: & $\begin{array}{l}\text { transp. \& urban planning < MANUSCRIPT CLASSIFICATION, computational } \\
\text { methods < type of paper to review, planning < Transportation, } \\
\text { transportation structures < Construction, transportation < Computer } \\
\text { Applications }\end{array}$ \\
\hline
\end{tabular}




\title{
Travel demand modeling to simulate traffic loads for pavement deterioration curves: dealing with aggregate data at urban and regional scales
}

\author{
Md. Shohel Reza Amin \\ Research Assistant, Dept. of Building, Civil and Environmental Engineering, \\ Concordia University, 1515 St. Catherine Ouest \\ Montreal, QC H3G1M8, Canada \\ Tel: +14389364119. Fax: +1-514-848-7965. \\ Email: md_amin@encs.concordia.ca \\ (Corresponding Author)
}

Luis E. Amador-Jiménez

Assistant Professor, Dept. of Building, Civil and Environmental Engineering, Concordia University, 1515 St. Catherine Ouest Montreal, QC H3G1M8, Canada

Tel: +1-514-848-2424 (ext. 5783). Fax: +1-514-848-7965.

Email: luis.amador@concordia.ca 


\title{
Travel demand modeling to simulate traffic loads for pavement deterioration curves: dealing with aggregate data at urban and regional scales
}

\begin{abstract}
:
Traditional pavement management system uses historical data on traffic volume or traffic growth rate to develop the pavement deterioration curves. This study simulates the traffic loads on regional and urban road networks to estimate the pavement deterioration curves applying travel demand models at urban and regional scales during the period of 2013-2062. Highways 1, 2, 7 , 15, 16, 102 and 104 connecting the Atlantic Provinces of Canada are considered as the case study at regional scale. Arterial and local roads of both rigid and flexible pavement types in Montreal city are considered as the case study at urban scale. The TRANUS integrates spatial input-output and transportation models to simulate interprovincial freight movement on the regional road network. Urban transportation planning system (UTPS) simulates the urban traffic on the road network of Montreal city. The accumulated traffic loads (ESALs) are calculated based on the predicted $A A D T$ and locally observed truck distributions combined with truck factors. Roughness progression on regional highways and urban roads is estimated by applying regression model of international roughness index (IRI). The $I R I$ will be 35.71, 43.33, 31.62 and 30.67 for flexible-arterial, rigid-arterial, flexible-local and rigid-local roads during the period of 2013-2062, respectively. Comparative evaluation of with and without simulated traffic reveals that the impact of simulated traffic is highest on the pavement structure of highway 2 and 1 at regional level and rigid-arterial and flexible roads of Montreal city. This study improves the traditional method of estimating pavement deterioration by incorporating the simulated traffic and traffic loads into the pavement performance function.
\end{abstract}


Keywords: Travel demand; annual average daily traffic; equivalent single axle loads; spatial input-output; urban transportation planning system; roughness progression.

\section{Introduction}

The appropriate and effective pavement performance curves are the fundamental components of pavement management system (PMS). These performance curves have significant features in PMS to prioritize the maintenance treatments, estimate the long-range investment requirement, estimate the consequences of budget allocation for maintenance treatments on future pavement condition and execute the life-cycle economic evaluation of the pavement (Amin and AmadorJiménez 2014). Lack of appropriate and effective pavement performance models in PMS makes the highway system costly and causes optimal pavement design, timing and selection of maintenance and rehabilitation $(\mathrm{M} \& \mathrm{R})$ operations impossible (Amin and Amador-Jiménez 2014). Early PMSs did not have performance curves rather they evaluated only the current pavement condition. Later, the simplified performance curves were introduced based on the engineering opinions on the expected design life of different M\&R actions (Amin 2015). The only predictive variable of these performance curves was the pavement age. The existing prediction models recognize the annual average daily traffic $(A A D T)$, equivalent single axle loads $(E S A L s)$, pavement age and structural number $(S N)$ as the most important factors of pavement deterioration (Archilla 2006; Yu et al. 2007; Santos and Ferreira 2013; Sathaye et al. 2010).

Traditional PMS uses historical data on traffic volume or traffic growth rate to develop the pavement deterioration curves. But traffic volume and distribution are related to economy, land 
use and travel behavior etc. Even a single shift of government policy on land use, economy and transportation can change the distribution and volume of traffic. To understand the impact of actual traffic loads on the pavement deterioration in long-run, traffic should be simulated by integrating economy, land use and transportation models.

This study simulates the traffic loads on regional and urban road networks applying travel demand models in order to estimate the pavement deterioration curves during the period of 20132062. This study assumes that pavement structure has 50 years life-span. Highways 1, 2, 7, 15, 16, 102 and 104 connecting the Atlantic Provinces of Canada (APC) are considered as the case study at regional scale. Arterial and local roads of both rigid and flexible pavement types in Montreal city are considered as the case study at urban scale. Aggregate data of land use, regional economy, trade flow and travel behavior are used and generated in the travel demand models to simulate the traffic volumes and loads.

\section{Literature review}

Pavement deterioration modeling has deterministic and stochastic approaches. Major differences between these approaches are model development concepts, modeling process or formulation, and output format of the models (Amin 2015). American Association of State Highway and Transportation Officials (AASHTO) developed the present serviceability index (PSI) for the flexible pavement (AASHTO 1985). The PSI and $18 \mathrm{kip} E S A L s$ are the main factors of pavement performance along with other factors such as materials properties, drainage and environmental conditions, and performance reliability (Abaza et al. 2001; Amin 2015). Abaza et al. (2001) developed pavement performance curve plotting PSI versus time or ESALs. Several studies also 
estimated PSI and pavement condition index $(P C I)$ based on the AASHO Road Test (Santos and Ferreira 2013; Lee et al. 1993; Li et al. 1997). These studies applied historical or inspection data of traffic volume to calculate ESALs.

Arizona Department of Transportation (ADOT) develops site-specific modeling approach based on historical performance data stored in the database (Li et al. 2006). Historical performance data for each individual section since the last rehabilitation or construction is analyzed to predict the future performance ( $\mathrm{Li}$ et al. 2006). Nevada Department of Transportation (NDOT) developed sixteen deterministic performance models for different pavement M\&R treatments in 1992 based on the historical performance data (Sebaaly et al. 1996; Amin 2015). Saleh, et al. (2000) developed a mechanistic roughness model relating the roughness with number of load repetitions, axle load, and asphalt layer thickness. The model applied vehicle dynamic analysis to estimate the dynamic force profile. The model also used the finite element structural analysis to estimate the roughness change of pavement surface for each load repetition (Amin 2015). George et al. (1989) carried out various regression analyses to develop empirical-mechanistic performance models for the highways in Mississippi based on the pavement condition data during the period of 1986-1988 (Amin 2015). The constructed performance models were evaluated based on the rational formulation, behavior of the models and statistical parameters. The exponential and power functions of both concave and convex shapes were identified as the statistically significant functions (Amin 2015). Smadi and Maze (1994) determined the PCI for the Iowa Interstate 80 based on the 10 years traffic data. The performance curve of $P C I$ was a function of only the total number of $18 \mathrm{kip} E S A L s$ that the pavement had experienced (Amin 2015). 
Archilla (2006) used panel data or repeated measurement data in the mixed-effects approaches to develop an empirical nonlinear model of rutting progression on asphalt concrete pavements. Kobayashi et al. (2010) estimated the Markov transition probability matrices (TPMs) for pavement deterioration based on the homogeneous and periodical inspection data. Ortiz-García et al. (2007) developed three methods to estimate TPMs for pavement deterioration modeling assuming that historical condition data were available, regression curve was developed from original data and yearly condition data were available. Ortiz-García et al. (2007) concluded that the yearly condition data provided the most appropriate method for determining TPMs. BenAkiva et al. (1993) developed a framework for the analysis of infrastructure performance and the planning of inspection and $M \& R$ activities. This framework modeled the measurement errors in performance indicators, treated the key variable as a latent variable and analyzed the uncertainties in infrastructure condition measurement and performance forecasting. Yu et al. (2007) proposed the linear mixed effects model (LMEM) to predict future conditions of a specific pavement section by a weighted combination of the average deterioration trend of pavement group and the past conditions of the specific pavement. The relative weights were determined by the number of past condition measurements available and the degree of variations of the measured past conditions for the specific pavement. The deterioration trend of each pavement section was obtained by parallel shifting of the group deterioration trend. Yu et al. (2007) assumed that the deterioration trend of all pavement sections in a group is similar and is a function of their present condition, regardless of age. 
Studies on pavement deterioration modeling have not yet addressed how dynamic traffic loads vary and impact on pavement structure during the life-span of the pavement as an interactive result of land use, economy and transportation modeling.

\section{Methodology}

This study has been executed in two main steps: simulation of traffic volumes and loads and pavement performance modeling. The flowchart of the methodology is shown in Figure 1.

Figure 1: Flow chart of methodology

\section{Integration of land use and transportation (ILUT) models}

Travel demands are simulated from ILUT models that measure the spatial interaction of land use and transport system. The spatial interaction predicts the traffic flows using the spatial characteristics of different traffic analysis zones (TAZs) such as distribution of works and employment, and travel cost, etc. (Torrens, 2000). Several ILUT models developed by various researchers and organizations such as Integrated Transportation Land Use Package (ITLUP), MEPLAN, TRANUS, MUSSA (Modelo de Uso de Suelo de Santiago), NYMTC-LUM, UrbanSim, BOYCE (Boyce et al. 1992), DELTA (Simmonds, 2001), ILUTE (Miller and Salvini, 2001), IMREL (Anderstig and Mattsson, 1998), IRPUD (Wegener, 2004), KIM (Rho and Kim, 1989), LILT (Mackett, 1991), METROSIM (Anas, 1994), PECAS (Hunt and Abraham, 2003), POLIS (Caindec and Prastacos, 1995), RURBAN (Miyamoto and Udomsri, 1996), STASA (Haag, 1990), TLUMIP (ODOT, 2002), TRESIS (Hensher and Ton, 2001). 
This study assesses the widely practiced ILUT models to determine the best applicable ILUT models for travel demand modeling with aggregate data at the urban and regional scale (Table 1). The ITLUP, MEPLAN and TRANUS models are Zone-based (typically large zones) because of the data constraint problem for the ITLUP model and non-representation of the technical coefficients for small zones in the MEPLAN and TRANUS models. The NYMTC-LUM model is based on the small zones but it does not represent the micro-scale.

[Table 1]

The MEPLAN and TRANUS have built-in network modeling capabilities to estimate the travel demand. The MUSSA, NYMTC-LUM and UrbanSim are 'connected' to four-stage travel demand modeling systems. The ITLUP can function either way. The ITLUP, MEPLAN and TRANUS are fully integrated models that use the composite utilities derived from the mode choice and land use models. These models ensure the internal consistency between the land use and transport components of the modeling system. The MUSSA, NYMTC-LUM, and UrbanSim use the composite utilities derived from destination choice models, either explicitly or implicitly. These models are very practical and indicate that the residential location processes are relatively long run in nature and depends upon a variety of factors. However, the MUSSA, NYMTC-LUM, and UrbanSim are more applicable to residential choice modeling (Hunt, et al. 2005).

This study applies the UTPS of ITLUP and TRANUS models to simulate the travel demand at urban and regional scales based on the comparative evaluation off ILUT models, respectively. The ITLUP and TRANUS models include all urban subsystems, have internal ability to model 
the transportation, simultaneously determine the transport and location, have multiple-path assignment approach for route-choice, are applicable with the aggregate data, are fully integrated models and use the composite utilities derived from the mode choice model. The major advantages of TRANUS as a regional ILUT model are that it explicitly considers the production and consumption of goods and services and applies spatial input-output (SIO) model that is a standard method of simulating the trade flow in the regional economics.

\section{TRANUS - integration of spatial input-output and transportation models at regional scale}

This study predicts interprovincial trade flow and freight movement on the regional highways connecting APC during the period of 2013-2062. The SIO model estimates the trade flow of goods and services for which the factors of production are private consumption, gross investment, government spending (both federal and provincial), and net exports. The fundamental assumption of the SIO model is that every sector requires input(s)/production factor(s) from other sector(s) except in the case of basic productive activities. The induced production at each province can be calculated based on the demand from one or more sectors at other provinces. The induced production is allocated among provinces through spatial distribution functions and demand. The allocation of induced production among different provinces causes trade flows (Amador-Jimenez and Amin 2013).

The total demand for sector $n$ in a particular province $i\left(T D_{i}^{n}\right)$ is calculated by Equation 1 (Modelistica 2008; Amador-Jimenez and Amin 2013).

$$
T D_{i}^{n}=\sum I D_{i}^{m n}+E D_{i}^{n} \quad \forall I D_{i}^{m n}=\left(E_{i}^{n, t-1}+\Delta E_{i}^{n, t} * W_{i}^{n, t}\right) * P D_{i}^{m n}
$$


$P D_{i}^{m n}=P D \min ^{m n}+\left(P D \max { }^{m n}-P D \min ^{m n}\right) * \exp -\delta^{m n} U_{i}^{n} \forall U_{i}^{n}=\frac{P D_{i}^{m n}}{\left[\min \left(P D_{i}^{m n}\right)\right]^{\theta^{m}}}(1)$

Where $I D_{i}^{m n}$ is the amount of inputs $n$ demanded by sector $m$ in province $i ; E_{i}^{n, t}$ is the total production of sector $n$ in province $i$ for time $t ; E_{i}^{n, t-1}$ is the total production of sector $n$ in province $i$ for time $t-1 ; \Delta E_{i}^{n, t}$ is the growth of production of sector $n$ in province $i$ between time $t$ 1 and $t ; W_{i}^{n, t}=\frac{A_{i}^{n, t}}{\sum_{i} A_{i}^{n, t}}$ is the proportion of the increment of $n$ allocated to province $i$ for time $t$; $E D_{i}^{n}$ is the exogenous demand for $n$ from zone other than five provinces and considered as zero; $P D_{i}^{m n}$ is the amount of production of sector $n$ demanded by a unit of sector $m$ in province $i$; $P D \min ^{m n}$ is the minimum amount of $n$ required by a unit production of $m$; PDmax ${ }^{m n}$ is the maximum amount of $n$ required by a unit production of $m ; \delta^{m n}$ is the elasticity parameter of $m$ with respect to the cost of input $n ; U_{i}^{n}$ is the disutility function of sector $n$ in province $i$; and $\theta^{\mathrm{m}}=$ degree of scaling (if utility function is fully scaled $\theta^{\mathrm{m}}=1$, otherwise zero).

The demand for production of good/sector $n$ in province $j$ is the product of the total demand for $n$. The production of $n$ in province $j$ is demanded by other provinces is given by Equation 2 (Modelistica 2008; Amador-Jimenez and Amin 2013).

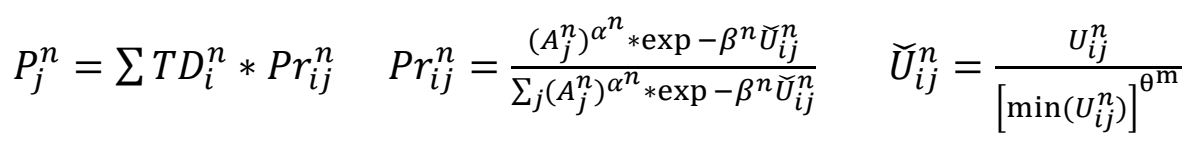

Where $P r_{i j}^{n}$ is the probability that the production of sector $n$ demanded in province $i$ is located in province $j ; A_{j}^{n}$ is the attractor term for the production of $n$ in $j ; \alpha^{n}$ is a parameter that regulates the 
relative importance of the attractor versus the utility function in the location of sector $n$; $\beta^{n}$ is the dispersion parameter of the multinomial logit model; and $U_{i}^{n}$ is the utility function of sector $n$ between province $i$ and $j$.

Freight demand for transporting goods and services among different provinces is estimated following Equation 3 (Modelistica 2008).

$F_{i j}=\sum_{n}\left(P_{i j}^{n} \frac{v_{o l}^{n} p c^{n}}{t_{i m e}^{n}}+P_{j i}^{n} \frac{v_{o l^{n}} c p^{n}}{t_{i m e^{n}}}\right)$

Where $F_{i j}$ is the freight flow from province $i$ to province $j ; P_{i j}^{n}$ is the production of sector $n$ located at province $j$ and consumed in province $i ; P_{j i}^{n}$ is the production of sector $n$ located at province $i$ and consumed in province $j$; $v o l^{n}$ is the value-to-volume factor for the economic flow of sector $n$; time $e^{n}$ is the time factor for the economic flow of sector $n ; c p^{n}$ is the proportion of economic flow of sector $n$ that moves in the direction consumption to production; $p c^{n}$ is the proportion of economic flow of sector $n$ that moves in the direction production to consumption.

\section{UTPS - integration of land use and transportation models at urban scale}

This study simulates the traffic volume on each road segment of Montreal road network for every 5-years period of 50 years (2013-2062) applying UTPS model. The discrete choice model is applied to estimate the trip generations from different boroughs of Montreal city using disaggregate household or individual level data of origin-destination survey 2008 (Equation 4). Trip generation is the function of gender, age, personal and household income, occupation, family size, auto ownership, number of children in the household, land use, and residential 
density (Caliper 2005). This study considers household size, auto ownership and occupation as the explanatory variables of trips per household for business, works and educational purposes during both peak and off-peak hours. Individual decisions to make trips are aggregated to estimate the total number of trip produced from the boroughs of Montreal city. Equation 5 aggregates the individual probabilities of trip making to predict the total number of trips produced from the boroughs (Caliper 2005).

$$
\begin{aligned}
& P_{n}(1)=\frac{1}{1+e^{\beta\left(X_{0 n}-X_{1 n}\right)}} \\
& S(i)=\frac{\sum_{c=1}^{C} N_{c}\left[\frac{\sum_{n=1}^{N_{S C} P_{n}(i)}}{N_{s c}}\right]}{N_{T}}
\end{aligned}
$$

Where $P_{n}(1)$ is the probability of $n$ person make a trip; $\beta$ is the vector of coefficients that is estimated by the model; $X_{0 n}$ is the vector of explanatory variables in person $n$ utility of not making a trip; $X_{1 n}$ is the vector of explanatory variables in person $n$ utility of making a trip; $S(i)$ is aggregate forecast of number of trips; $N_{S}$ is number of decision makers in the sample; $N_{s c}$ is number of decision makers in different groups $C ; N_{T}$ is number of decision makers in the populations; $N_{C}$ is number of decision makers in the population of groups $C$; and $C$ is number of groups (Caliper 2005).

The predicted trips are spatially distributed among boroughs of Montreal city by applying a doubly-constrained gravity model (Equation 6) (Caliper 2005). The model balances the trip productions and then factors the calculated attractions so that they normalize to the input 
attractions. These two steps are then enveloped in an iterative loop until the convergence has been achieved (Caliper 2005).

$T_{i j}=A_{j} \times P_{i} \times f\left(d_{i j}\right) \times a_{i} \times b_{j}$

$a_{i}=\frac{1}{\sum_{\text {all zones } z} b_{z} \times A_{z} \times f\left(d_{i z}\right)} \quad$ and $\quad b_{j}=\frac{1}{\sum_{\text {all zones } z} a_{z} \times P_{z} \times f\left(d_{z j}\right)}$

Where $T_{i j}$ is the predicted traffic flow from borough $i$ to $j ; P_{i}$ is the predicted number of trips produced in borough $i ; A_{j}$ is the predicted number of trips attracted to borough $j ; f\left(d_{i j}\right)$ is friction factor between boroughs $i$ and $j$. Friction function is the impedance function of travel time and cost (Caliper 2005).

A multinomial Logit (MNL) model is applied to estimate the choice of modes (car driving alone, car share, bus, metro and bicycle) by travelers assuming that the utility of an alternative mode is a function of the choice determinants, unknown parameters and an i.i.d Gumbel-distribution error term. Finally, deterministic User Equilibrium (DUE) model is applied to simulate the $A A D T$ on each road segment of Montreal city. The DUE method applies an iterative process to achieve a convergent solution so that no travelers can improve their travel times by shifting routes (Caliper 2005).

\section{Pavement performance modeling}

The main purpose of this study is to estimate the effect of simulated traffic loads on the deterioration of pavement structure. This study estimates the deterioration of pavement structures based on the regression modeling of roughness progression given by Equation 7 (Paterson and 
Attoh-Okine 1992; Watanatada et al. 1987). Equation 7 shows that roughness progression (International Roughness Index, $I R I)$ is the function of initial as-built quality $\left(\operatorname{IRI}_{O}\right), E S A L s$ at time $t\left(E S A L_{t}\right), S N$, and mean environmental exposure (Thornthwaite moisture index TMI, $m$ ). However, the decision variable of predicting IRI is ESALs in this method. The ESALs are calculated based on the predicted $A A D T$ and locally observed truck distributions combined with truck factors. The Federal Highway administration (2011) defines the distribution and truck factors for truck classes of 4, 5, 6, 7, 8, 9, 10, 11, 12 and 13.

$$
I R I_{t}=e^{m t}\left[I R I_{0}+a(1+S N)^{-5} \cdot E S A L_{t}\right]
$$

This study estimates $S N$ applying categorical values of thickness of pavement's layers for broader categories of $A A D T$ both for flexible and rigid pavements adopted from the report of Cement Association of Canada (2012). The $S N$ follows the computation method developed by the 1993 AASHTO Flexible Pavement Structural Design. The actual layer thicknesses are converted to $S N$ using a layer coefficient that represents the relative strength of the construction materials in that layer (AASHTO 1993). Additionally, all layers below the surface layer are assigned a drainage coefficient that represents the relative loss of strength in a layer due to its drainage characteristics and the total time it is exposed to near-saturation moisture conditions (AASHTO 1993).

The TMI for all road segments of Montreal road network is equal because of locating in the same TMI zone. The TMI is identified as $0.07,0.074$ and 0.08 for the three environmental zones with 
a moisture index of 60, 80 and 100 within APC, respectively (Natural Resources Canada 1995). The $I R I_{0}$ is set between 0.7 and $1 \mathrm{~m} / \mathrm{km}$ depending on the highway and coefficient $a$ is set to 265 .

\section{Results}

This study simulates $A A D T$ at urban and regional road networks during the period of 2013-2062 applying the travel demand models. The pavement deterioration curves are estimated for regional and urban roads applying Equation 7.

\section{Travel demand modeling}

\section{Travel demand modeling at regional scale}

Freight flow between APC on regional road networks is simulated during the period of 20132062 by applying Equation 1 and 2. The Exogenous and induced production (CAD million) of different sectors in the year 2013 is shown in Table 2. Table 3 depicts the demand function that is the amount of production of a sector demanded by a unit of another sector in the year 2013.

[Table 2]

[Table 3]

Total demand and production of five APC during the period of 2013-2062 are shown in Figure 2. Figure 2 shows that the predicted production and demand of goods and services in New Brunswick is indifferent during the period of 2013-2062. In Nova Scotia, total demand and production will decrease during the same period. Total demand exceeds total production in Newfoundland and Labrador. In Quebec, total production is far higher than total demand and 
increasing at a higher rate than that of demand during the same period. In Prince Edward Island, the total demand is increasing at a higher rate than that of production (Figure 2).

Figure 2. Total demand and production of goods and services in Atlantic Provinces of Canada

Since this study is mainly focusing on the interprovincial flow of truck, the truck share of the interprovincial trade flow is only considered. It is assumed that an average-sized truck tentatively carries CAD 1 million worth of goods and services (Amador-Jiménez and Amin, 2013). The integration of SIO and transportation models estimates the annual average daily truck traffic (AADTT) for interprovincial trade flow. The AADTT for the year of 2013 is estimated 2446, $8170,953,611,581,231$ and 186 on highway $1,2,7,15,16,102$ and 104, respectively. Travel demand model is validated using the original data. Calibrated AADTT for interprovincial trade flow contributes $85 \%, 91 \%, 41 \%, 36 \%, 62 \%, 73 \%$ and $87 \%$ of total AADTT of highway 1, 2, 7, $15,16,102$ and 104, respectively.

Traffic loads (ESALs) are estimated based on the simulated AADT and the guideline developed by Federal Highway administration (2011). The accumulated traffic loads will be 38.23, 127.70, 14.89, 9.55, 9.07, 3.61 and 2.91 million ESALs on highway 1, 2, 7, 15, 16, 102, and 104 during the period of 2013-2062, respectively. The annual traffic loads will increase from 3.96 to 7.28 million on highway 2 during the period of 2013-2062 (Figure 3).

Figure 3: Equivalent Single Axle Loads (ESALs) on regional road networks

\section{Travel demand modeling at urban scale}


The logistic regression coefficients of discrete choice model give the change in the log odds of the trips per household for a one unit increase in the predictor variable such as auto ownership, persons per household and occupation (Table 4). Table 4 shows that the predictor variables are statistically significant for different trip purposes during both peak and off-peak hours except in the cases of auto ownership for business (peak hours), working (off-peak hours) and educational (off-peak hours) trips. Models shows that the value of parameter decreases with increasing auto ownership in Montreal city for working, business and education trips, thus confirming the hypothesis that the number of trips made decreases with auto ownership (Table 4). Montrealers prefers public transits for working, business and education trips rather than private cars in order to avoid the traffic congestion, parking fees and inadequate parking spaces at offices, business centers and educational institutions. Number of working and business trips taken increases with increasing number of persons per households but educational trips decrease with increasing persons per households during both peak and off-peak hours (Table 4). Employment has significantly positive impact on the business and working trips and negative impact on the educational trips (Table 4).

[Table 4]

The doubly-constrained gravity model (Equation 6) spatially distributes the generated trips among boroughs of Montreal city (Figure 4). For example, a total of 132029 trips are generated from Ville-Marie borough in an average day of the year 2013 and 20 percent of these trips are terminated within the same borough (Figure 4). The proportions of trips distributed from VilleMarie to Plateau Mont-Royal, Côte-des-Neiges-Notre-Dame-de-Grâce, Mercier-Hochelaga- 
Maisonneuve, Rosemont-La Petite Patrie, Ahuntsic-Cartierville, Sud-Ouest and Villeray - SaintMichel - Parc-Extension are $11 \%, 9 \%, 7 \%, 7 \%, 5 \%, 5 \%$ and 5\% in an average day of the year 2013, respectively (Figure 4).

Figure 4: Simulated origin-destination map of traffic flow in 2013

The MNL models estimate that the choice determinants (travel time and cost) are statistically significant for all modes. Travel time is inversely related to the utility of all modes except in the case of car-share riding (Table 5). Trip makers share ride to reduce the cost for long trip distance.

[Table 5]

The DUE model simulates the $A A D T$ on each road segment of Montreal city during the period of 2013-2062. For example, $A A D T$ will be increased by $6.8 \%, 6 \%, 5.8 \%$ and $5.2 \%$ on flexiblearterial, rigid-arterial, flexible-local and rigid-local roads during the period of 2008-2013, respectively (Table 6). The model is validated with original data of year 2008. Comparative evaluation of original and calibrated $A A D T$ shows that the overall $A A D T$ on the road network of Montreal city will be increased by $1.68 \%$ applying the travel demand model. The arterial-rigid and arterial-flexible roads observe the increases of $A A D T$ applying the model that are $9.05 \%$ and $7.88 \%$, respectively. However, local-rigid and local-flexible roads observe the decreases of $A A D T$ that are $5.13 \%$ and $4.40 \%$, respectively. The DUE model assign traffic on a road segment based on the performance function (travel time) that is the function of free-flow travel time, volume and capacity of road segment and calibration parameters. This is why; increment of $A A D T$ is observed on the arterial roads applying the travel demand model. However, travel 
behavior and choice to select a road by commuters are complicated and depend on various factors.

The $A A D T$ are converted to ESALs to estimate the accumulated traffic loads on each road segment of Montreal city. Data on type and distribution of vehicles on the road network of Montreal city are adopted from the report prepared by the Cement Association of Canada (2012). The accumulated ESALs will be 138, 120, 62 and 44 million on flexible-arterial, rigid-arterial, flexible-local and rigid-local roads during 2013-2062, respectively (Figure 5).

[Table 6]

Figure 5: Equivalent Single Axle Loads (ESALs) on urban road network of Montreal city

\section{Pavement performance modeling}

The deterioration curves (IRI) of pavement condition are developed for regional highways connecting APC and urban road network of Montreal city following Equation 7 (Figure 6 and 7). Figure 6 shows the IRI of selected highways during the 50-years period for different moisture index zones. For example, Highway 1 geographically locates within 100 and 80 TMI zones; Highway 2 and 7 locate within 100, 80 and 60 TMI zones; Highway 15 locates within 80 and 60 TMI zones; Highway 16 locates within 60 TMI zone; Highway 102 locates within 100 TMI zone; and Highway 104 locates within 80 TMI zone (Natural Resources Canada 1995). The IRI will be increased to 39.62, 29.35 and 24.03 for Highway 2 locate within 100, 80 and 60 TMI zones during the period of 2013-2062, respectively (Figure 6). In the case of urban road network of Montreal city, roughness progression will be $35.71,43.33,31.62$ and 30.67 for flexible- 
arterial, rigid-arterial, flexible-local and rigid-local roads during the same period, respectively (Figure 7).

Figure 6: International Roughness Index for regional road network of Atlantic Provinces of Canada during 2013-2062

Figure 7: International Roughness Index of road network of Montreal city during 2013-2062 To verify the effects of simulated traffic on pavement deterioration, this study predicts the IRI for controlled scenario - without simulated traffic. In case of controlled scenario, the $A A D T$ is controlled to constant and equivalent to base year traffic during the design period. This controlled scenario helps to determine the significance of simulated traffic in the evolution of IRI. For regional highways, the most significant change in roughness progress due to the simulated traffic is observed at highway 2 . The IRI of pavement structure with simulated traffic will be up to $9 \%$ higher than that at controlled scenario during the period of 2013-2062 (Figure 6 and 8). For highway 1, the IRI with simulated traffic will be $3 \%$ higher than that at controlled scenario during the same period (Figure 6 and 8). There are insignificant changes $(0-1 \%)$ in roughness progression of highways $7,15,16,102$ and 104 due to simulated traffic.

Figure 8: International Roughness Index for regional road network of Atlantic Provinces of Canada during 2013-2062 without simulated traffic

For road network of Montreal city, the most significant change in roughness progress due to the simulated traffic is observed at rigid-arterial roads. The $I R I$ of pavement structure with simulated traffic will be up to $19.04 \%$ higher than that at controlled scenario during the design period 
(Figure 7 and 9). The IRI for flexible-arterial, flexible-local and rigid-local roads with simulated traffic will be $10.56 \%, 5.07 \%$ and $3.67 \%$ higher than that at controlled scenario during the same period, respectively (Figure 7 and 9).

Figure 9: International Roughness Index of road network of Montreal city during 2013-2062 without simulated traffic

The estimated pavement performance curves for both regional and urban road networks defines the impact of simulated traffic loads on the pavement deterioration. This study improves the traditional method of estimating pavement deterioration by incorporating the simulated traffic and traffic loads into the pavement performance function.

\section{Conclusions}

Traditional pavement management system uses historical data on traffic volume or traffic growth rate to develop the pavement deterioration curves. But traffic volume and distribution are related to economy, land use and travel behavior etc. This study simulates the traffic loads on regional and urban road networks applying travel demand models to estimate the pavement deterioration curves at urban and regional scales during the period of 2013-2062. Highways 1, 2, 7, 15, 16, 102 and 104 connecting the Atlantic Provinces of Canada are considered as the case study at regional scale. Arterial and local roads of both rigid and flexible pavement types in Montreal city are considered as the case study at urban scale.

Interprovincial freight movement on the regional road network is simulated by TRANUS that integrates spatial input-output (SIO) and transportation models. Urban transportation planning 
system (UTPS) simulates the urban traffic on the road network of Montreal city for every 5 years during the period of 2013-2062. The integration of SIO and transportation models estimates the annual average daily truck traffic $(A A D T T)$ as 2446, 8170, 953, 611, 581, 231 and 186 on highway $1,2,7,15,16,102$ and 104 in the year of 2013, respectively. The UTPS model estimates the annual average daily traffic $(A A D T)$ will be increased by $6.8 \%, 6 \%, 5.8 \%$ and $5.2 \%$ on flexible-arterial, rigid-arterial, flexible-local and rigid-local roads during the period of 20082013. Traffic volumes are converted to accumulated traffic loads (ESALs) based on the predicted $A A D T$ and locally observed truck distributions combined with truck factors. The ESALs will be $38.23,127.70,14.89,9.55,9.07,3.61$ and 2.91 million on highway $1,2,7,15,16,102$, and 104 during the period of 2013-2062, respectively. The accumulated ESALs will be 138, 120, 62 and 44 million on flexible-arterial, rigid-arterial, flexible-local and rigid-local roads during 20132062, respectively.

Roughness progression on regional highways and urban roads is estimated by applying regression model of international roughness index (IRI). In the case of urban road network of Montreal city, roughness progression will be 35.71, 43.33, 31.62 and 30.67 for flexible-arterial, rigid-arterial, flexible-local and rigid-local roads during the period of 2013-2062, respectively. This study estimates IRI of the selected highways connecting Atlantic Provinces of Canada during the 50-years period for TMI zones. The IRI will be increased to 39.62, 29.35 and 24.03 for Highway 2 located within 100, 80 and 60 TMI zones during the period of 2013-2062, respectively. Comparative evaluation of with and without simulated traffic reveals that the impact of simulated traffic is highest on the pavement structure of highway 2 and 1 at regional level and rigid-arterial and flexible roads of Montreal city. This study improves the traditional 
method of estimating pavement deterioration by incorporating the simulated traffic and traffic loads into the pavement performance function.

\section{References}

AASHTO 1985. AASHTO Guide for the Design of Pavement Structures (Appendix EE). American Association of State Highway and Transportation Officials, Washington, D.C.

AASHTO 1993. AASHO Guide for the Design of Pavement Structures. American Association of State Highway and Transportation Officials, Washington, DC.

Abaza, K.A., Ashur, S.A., Abu-Eisheh, S.A., and Rabay'a, A. 2001. Macroscopic Optimum System for Management of Pavement Rehabilitation. Journal of Transportation Engineering, 127(6):493-500.

Amador-Jimenez, L.E., and Amin, M.S.R. 2013. Simulating Freight-traffic between Atlantic Canada and Quebec to Support Pavement Management on New Brunswick's Regional Highway. Journal of Infrastructure Systems, 19(3): 343-350.

Amin, M.S.R. 2015. The Pavement Performance Modeling: Deterministic vs Stochastic Approaches. In Numerical Methods for Multiscale and Multiphysics in Reliability and Safety. Edited by S. Kadry and A. El Hami. Springer, Switzerland. pp. 179-196.

Amin, M.S.R., and Amador-Jiménez, L. 2014. A performance-based Pavement Management System for the road network of Montreal city-a conceptual framework. In Asphalt Pavements. Edited by Y. Richard Kim. Taylor \& Francis Group, London. pp. 233-244.

Anas, A. 1994. METROSIM: A Unified Economic Model of Transportation and Land-Use. Alex Anas \& Associates, Williamsville, NY.

Anderstig, C., and Mattsson, L.-G. 1998. Modelling land-use and transport interaction: evaluations and policy analysis. In Network Infrastructure and the Urban Environment: Recent 
Advances in Land-Use/Transportation Modelling. Edited by L. Lundqvist, L. Mattsson, and T.J. Kim. Springer, Berlin/Heidelberg/New York. pp. 308-328.

Archilla, A.E. 2006. Repeated Measurement Data Analysis in Pavement Deterioration Modeling. Journal of Infrastructure Systems, 12(3):163-173.

Ben-Akiva, M., Humplick, F., and Madanat, S. 1993. Infrastructure Management under Uncertainty: The Latent Performance Approach. Journal of Transportation Engineering, 119(1): 43-58.

Boyce, D., Tatineni, M., and Zhang, Y. 1992. Scenario Analyses of the Chicago Region with a Sketch Planning Model of Origin-Destination Mode and Route Choice. Urban Transportation Center, University of Illinois, Chicago, IL.

Caindec, E.K., and Prastacos, P. 1995. A Description of POLIS. The Projective Optimization Land Use Information System. Association of Bay Area Governments, Oakland, CA.

Caliper 2005. Travel Demand Modeling with TransCAD 4.8. Caliper Corporation, Newton, MA. Cement Association of Canada 2012. Methodology for the Development of Equivalent Pavement Structural Design Matrix for Municipal Roadways- Montréal and Québec City: Including Maintenance \& Rehabilitation Schedules and Life Cycle Cost Analysis. Final Report, Applied Research Associates Inc., Ottawa.

Federal Highway Administration (2011). Highway Performance Monitoring System Manual. US Department of Transport, USA. Available $\quad$ from http://www.fhwa.dot.gov/ohim/hpmsmanl/appn1.cfm. [cited 18 July 2011].

George, K.P., Rajagopal, A.S., and Lim, L.K. 1989. Models for Predicting Pavement Deterioration. Transportation Research Record: Journal of the Transportation Research Board, 1215: $1-7$. 
Haag, G. 1990. Master equations. In Urban Dynamics. Designing an Integrated Model. Edited by C.S. Bertuglia, G. Leonardi, and A.G. Wilson. Routledge, London/New York. pp. 69-83.

Hensher, D., and Ton, T. 2001. TRESIS: A transportation, land use and environmental strategy impact simulator for urban areas. In Proceedings of the 9th World Conference on Transport Research, Seoul, South Koria, 22-27 July.

Hunt, J., and Abraham, J. 2003. Design and application of the PECAS land use modelling system. In Proceedings of the 8th International Conference on Computers in Urban Planning and Urban Management, Sendai, Japan, 27-29 May, CD-ROM Format.

Hunt, J.D., Kriger, D.S., and Miller, E.J. 2005. Current Operational Urban Land-use-Transport Modelling Frameworks: A Review. Transport Reviews, 25(3): 329-376.

Kobayashi, K., Do, M., and Han, D. 2010. Estimation of Markovian transition probabilities for pavement deterioration forecasting. KSCE Journal of Civil Engineering, 14(3): 343-351.

Lee, Y.-H., Mohseni, A., and Darter, M.I. 1993. Simplified Pavement Performance Models. Transportation Research Record: Journal of the Transportation Research Board, 1397:7-14.

Li, Y., Cheetham, A., Zaghloul, S., Helali, K., and Bekheet, W. 2006. Enhancement of Arizona Pavement Management System for Construction and Maintenance Activities. Transportation Research Record: Journal of the Transportation Research Board, 1974: 26-36.

Li, N., Haas, R., and Xie, W.-C. 1997. Investigation of Relationship Between Deterministic and Probabilistic Prediction Models in Pavement Management. Transportation Research Record: Journal of the Transportation Research Board, 1592:70-79.

Mackett, R.L. 1991. LILT and MEPLAN: a comparative analysis of land-use and transport policies for Leeds. Transport Reviews, 11:131-154.

Miller, E., and Salvini, P. 2001. The Integrated Land Use, Transportation, Environment (ILUTE) Microsimulation Modelling system: Description and current status. In The Leading Edge in 
Travel Behaviour Research. Edited by D. A. Henscher. 9th International Association for Travel Behaviour Research Conference, Gold Coast, Queensland, Australia.

Miyamoto, K., and Udomsri, R. 1996. An analysis system for integrated policy measures regarding land use, transport and the environment in a metropolis. In Transport, Land Use and the Environment. Edited by Y. Hayashi and J. Roy. Kluwer, Dordrecht. pp. 259-280.

Modelistica (2008). Mathematical Descriptions of TRANUS. Available from http://www.tranus.com/tranus-english. [cited 10 January 2011].

Natural Resources Canada. The National Atlas of Canada 1978-1995: Thornthwaites Classification Moisture Regions, Canada, 1995. Available from http://atlas.nrcan.gc.ca/site/english/maps/archives/5thedition/environment/climate/mcr4096 [cited 24 April 2012].

ODOT, 2002. Oregon Department of Transportation. [Online] Available from http://www.odot.state.or.us/tddtpau/ [cited 11 January 2014].

Ortiz-García, J.J., Costello, S.B., and Snaith, M.S. 2007. Derivation of Transition Probability Matrices for Pavement Deterioration Modeling. Journal of Transportation Engineering, 132(2):141-161.

Paterson, W.D.O., and Attoh-Okine, B. 1992. Summary of Models of Pavement Road Deterioration Based on HDM-III. Transportation Research Record: Journal of the Transportation Research Board, 1344: 99 - 105.

Rho, J.H., and Kim, T.J. 1989. Solving a three-dimensional urban activity model of land use intensity and transport congestion. Journal of Regional Science, 29: 595-613.

Saleh, M.F., Mamlouk, M.S., Owusu-Antwi, E.B. 2000. Mechanistic Roughness Model based on Vehicle-Pavement Interaction. Transportation Research Record: Journal of the Transportation Research Board, 1699:114-120. 
Santos, J., and Ferreira, A. 2013. Life-cycle cost analysis system for pavement management at project level. International Journal of Pavement Engineering 14(1): 71-84.

Sathaye, N., Horvath, A., and Madanat, S. 2010. Unintended impacts of increased truck loads on pavement supply-chain emissions. Transportation Research Part A 44:1-15.

Sebaaly, P.E., Hand, A., Epps, J., and Bosch, C. 1996. Nevada's Approach to Pavement Management. Journal of the Transportation Research Record: Journal of the Transportation Research Board, 1524:109-117.

Simmonds, D. 2001. The objectives and design of a new land-use modelling package: DELTA. In Regional Science in Business. Edited by G. Clarke and M. Madden. Springer, Berlin/Heidelberg. pp. 159-188.

Smadi, O.G., and Maze, T.H. 1994. Network Pavement Management System Using Dynamic Programming: Application to Iowa State Interstate Network. Third International Conference on Managing Pavements, Transportation Research Board, National Research Council, San Antonio, Texas.

Torrens, P.M. 2000. How Land-Use-Transportation Models Work. Centre for Advanced Spatial Analysis, University College London, London, UK.

Watanatada, T., Harral, C.G., Paterson, W.D.O., Dhareshwar, A.M., Bhandari, A., and Tsunokawa. K. 1987. The Highway Design and Maintenance Standard Model. The John Hopkins University Press, Washington DC, USA.

Wegener, M. 2004. Overview of Land-Use Transport Models. In Transport Geography and Spatial Systems. D. A. Hensher \& K. Button. Pergamon/Elsevier Science, Kidlington, UK. pp. 127-146. 
Yu, J., Chou, E.Y.J., and Luo, Z. 2007. Development of Linear Mixed Effects Models for Predicting Individual Pavement Conditions. Journal of Transportation Engineering 133(6): 347354. 


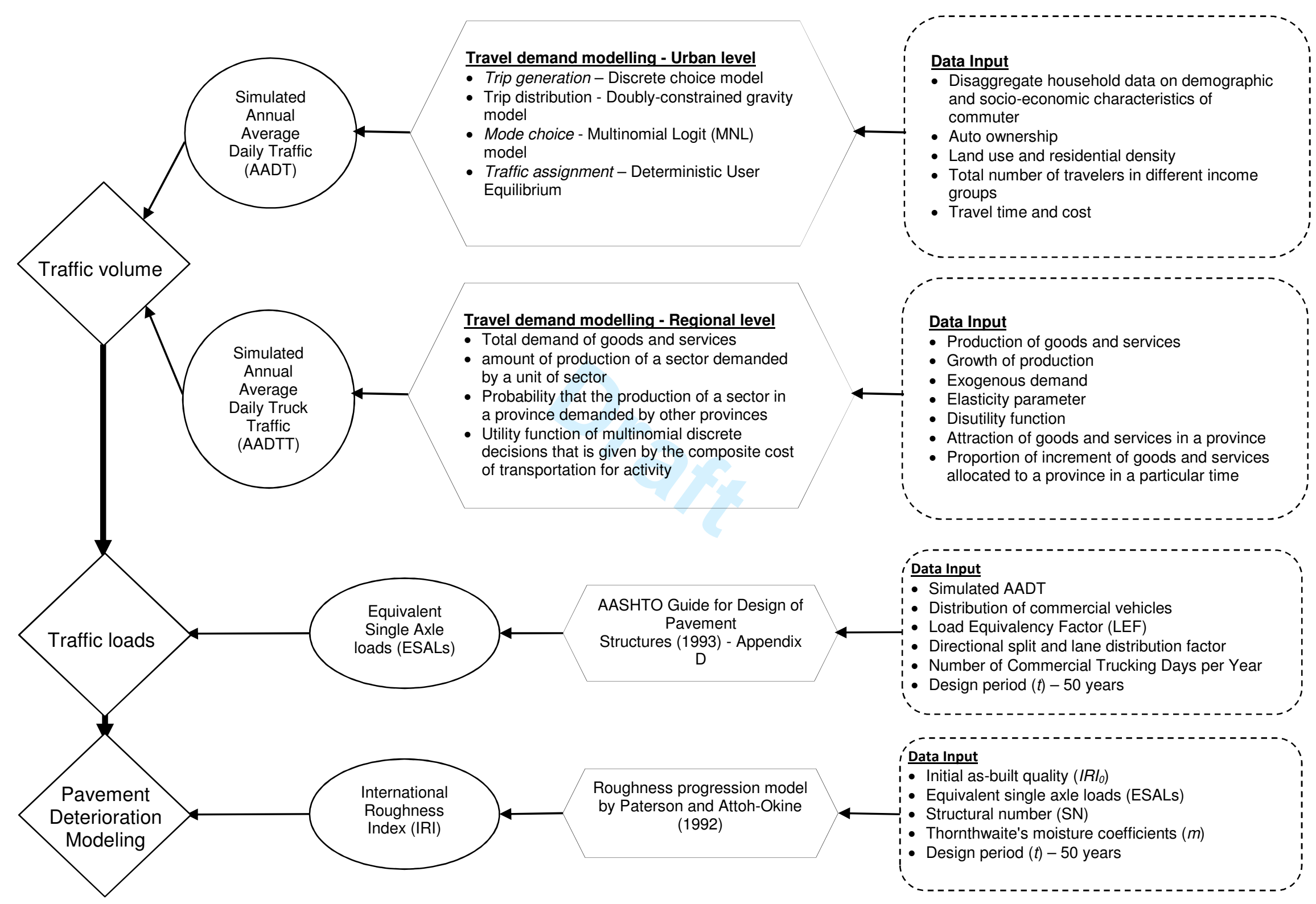

https://mc06.manuscriptcentral.com/cjce-pubs 


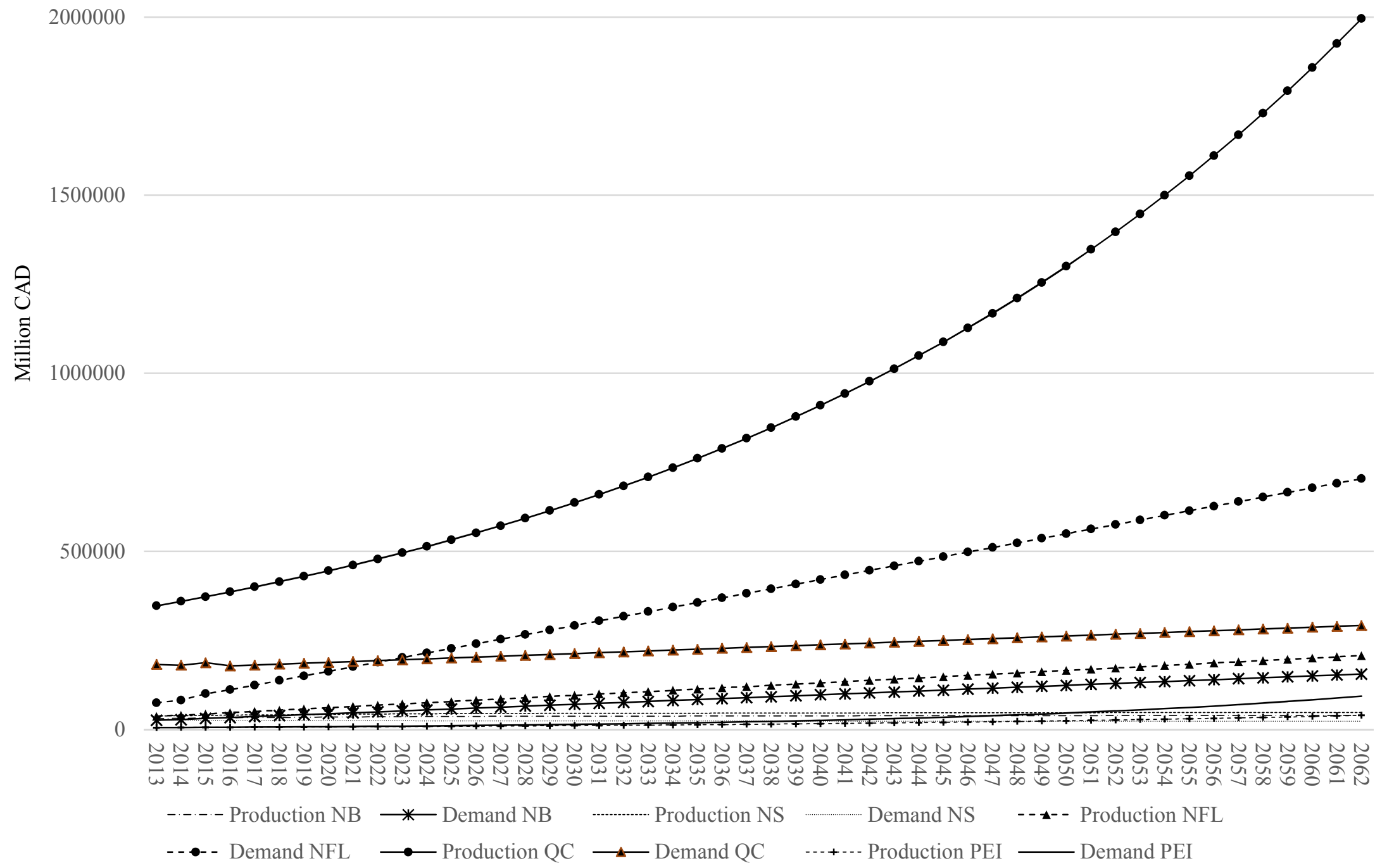




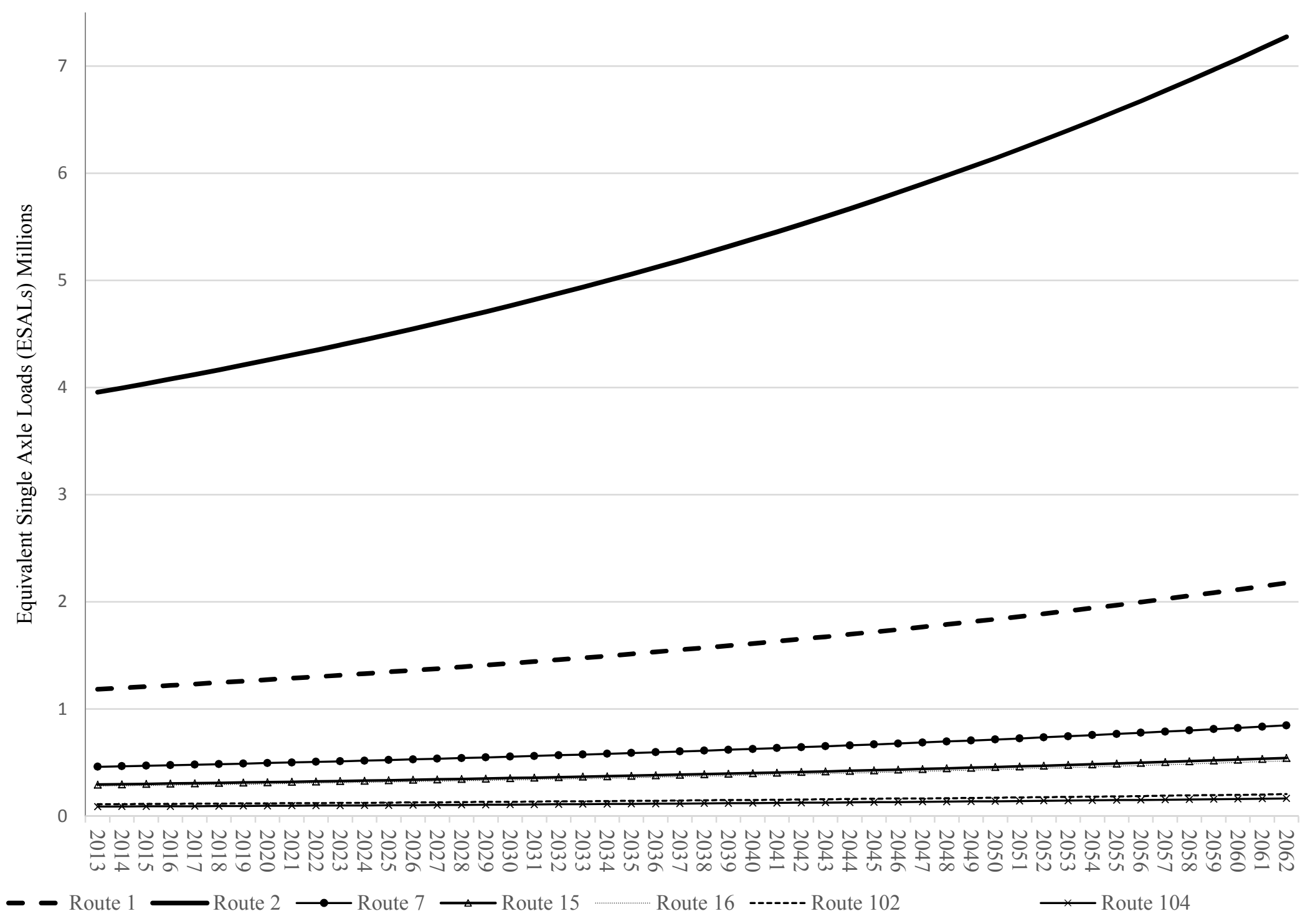




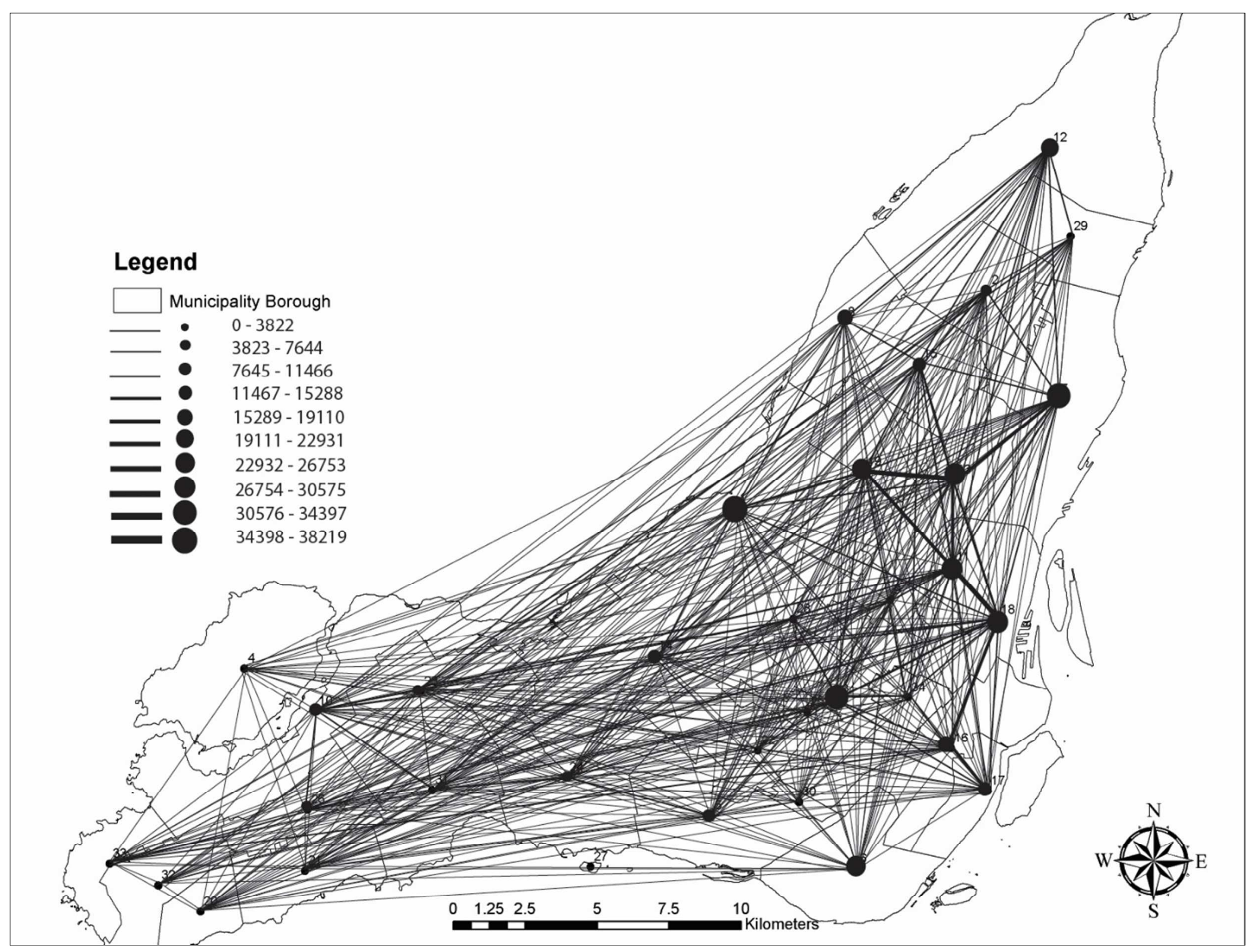

https://mc06.manuscriptcentral.com/cjce-pubs 


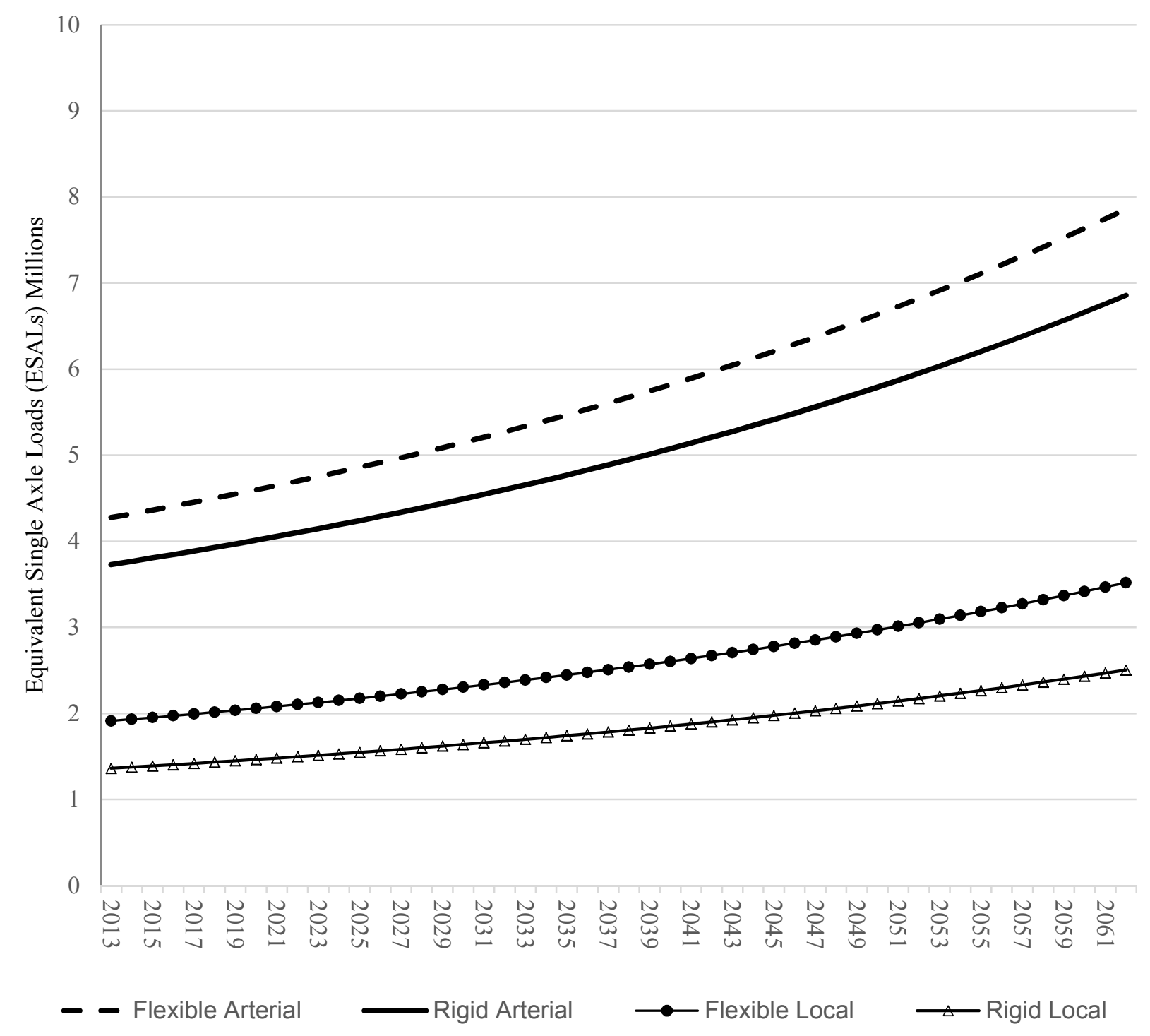




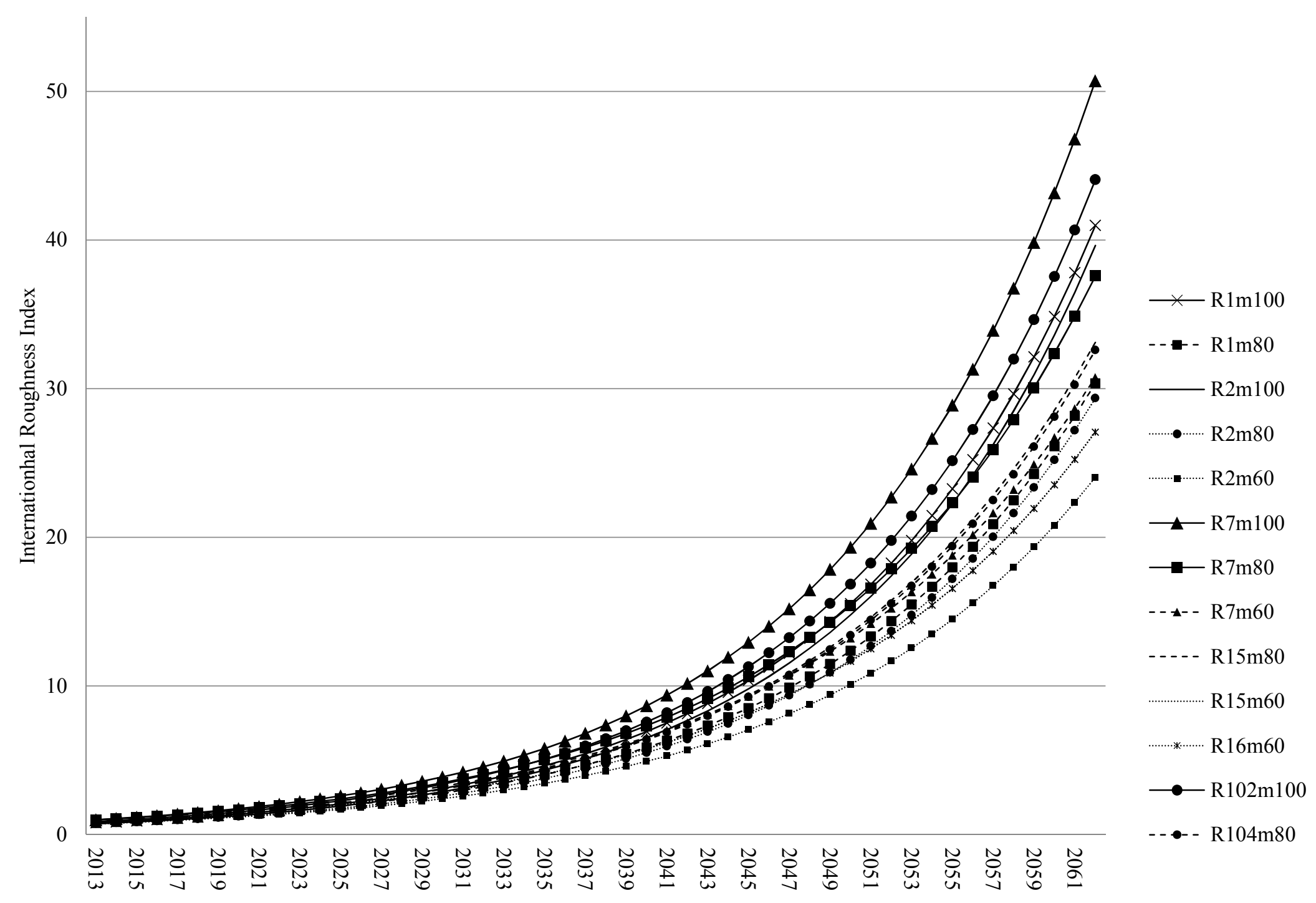

Periods 


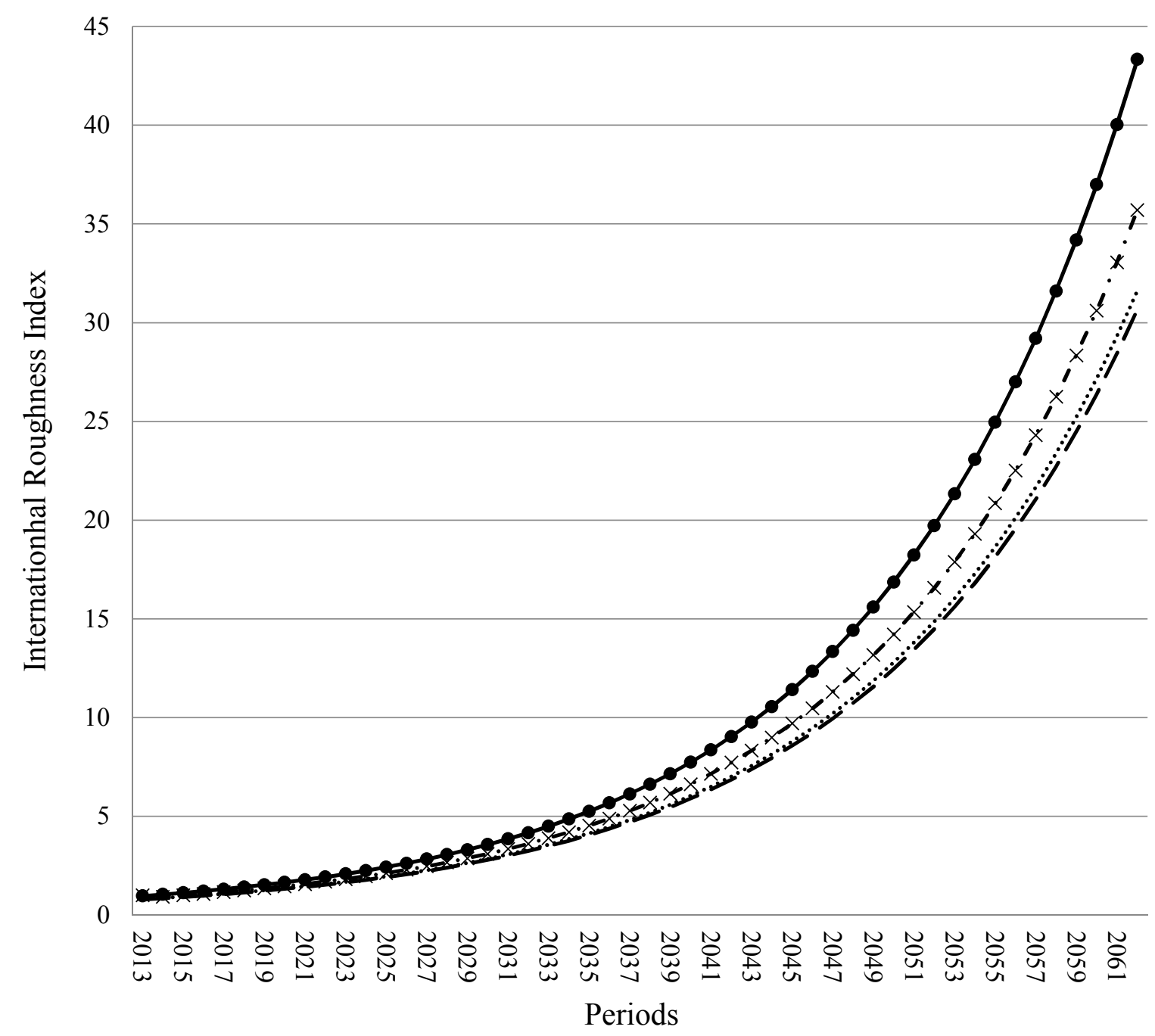

- $x$ - Flexible Arterial $\rightarrow$ Rigid Arterial …….. Flexible Local $-\longrightarrow$ Rigid Local 


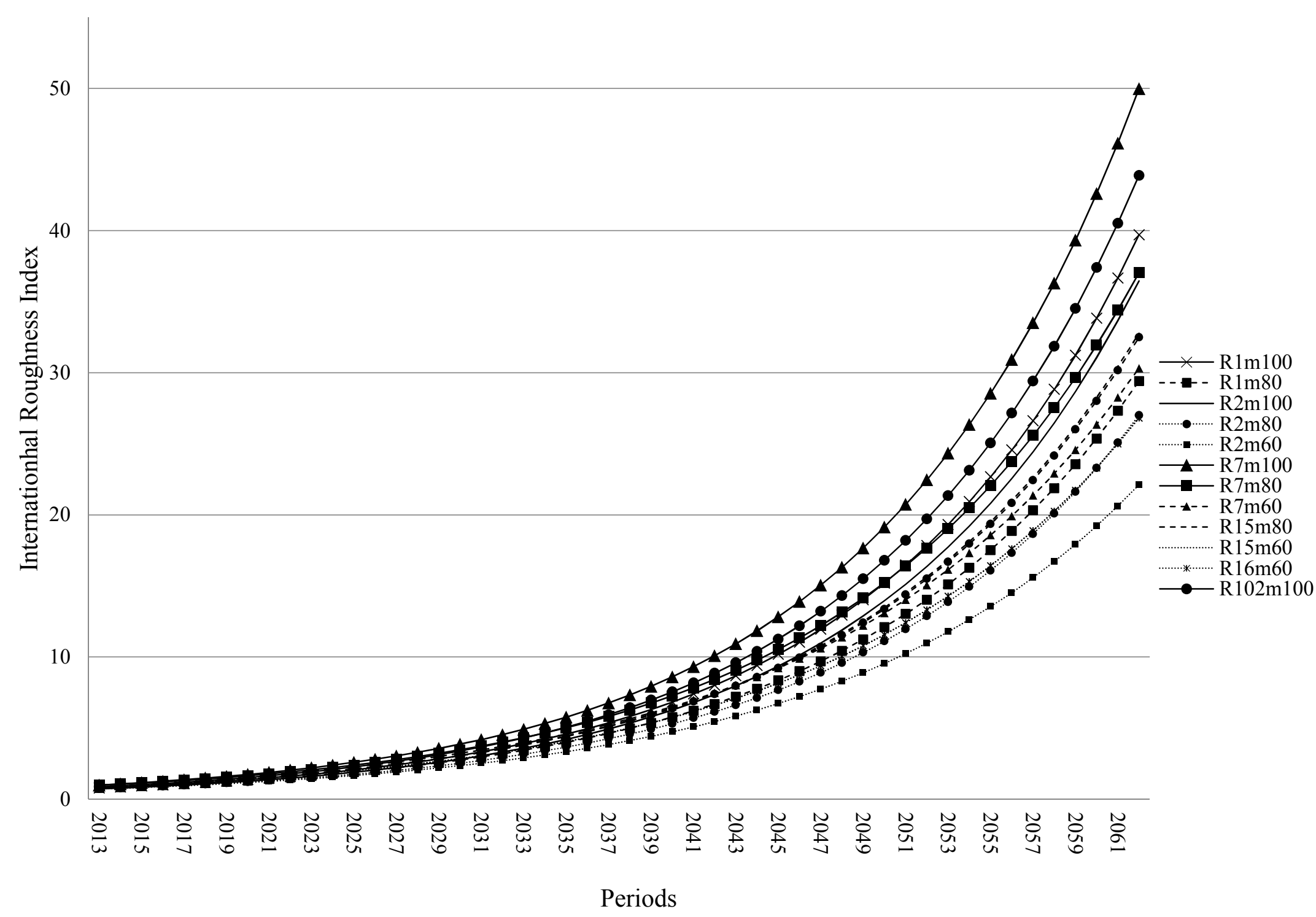




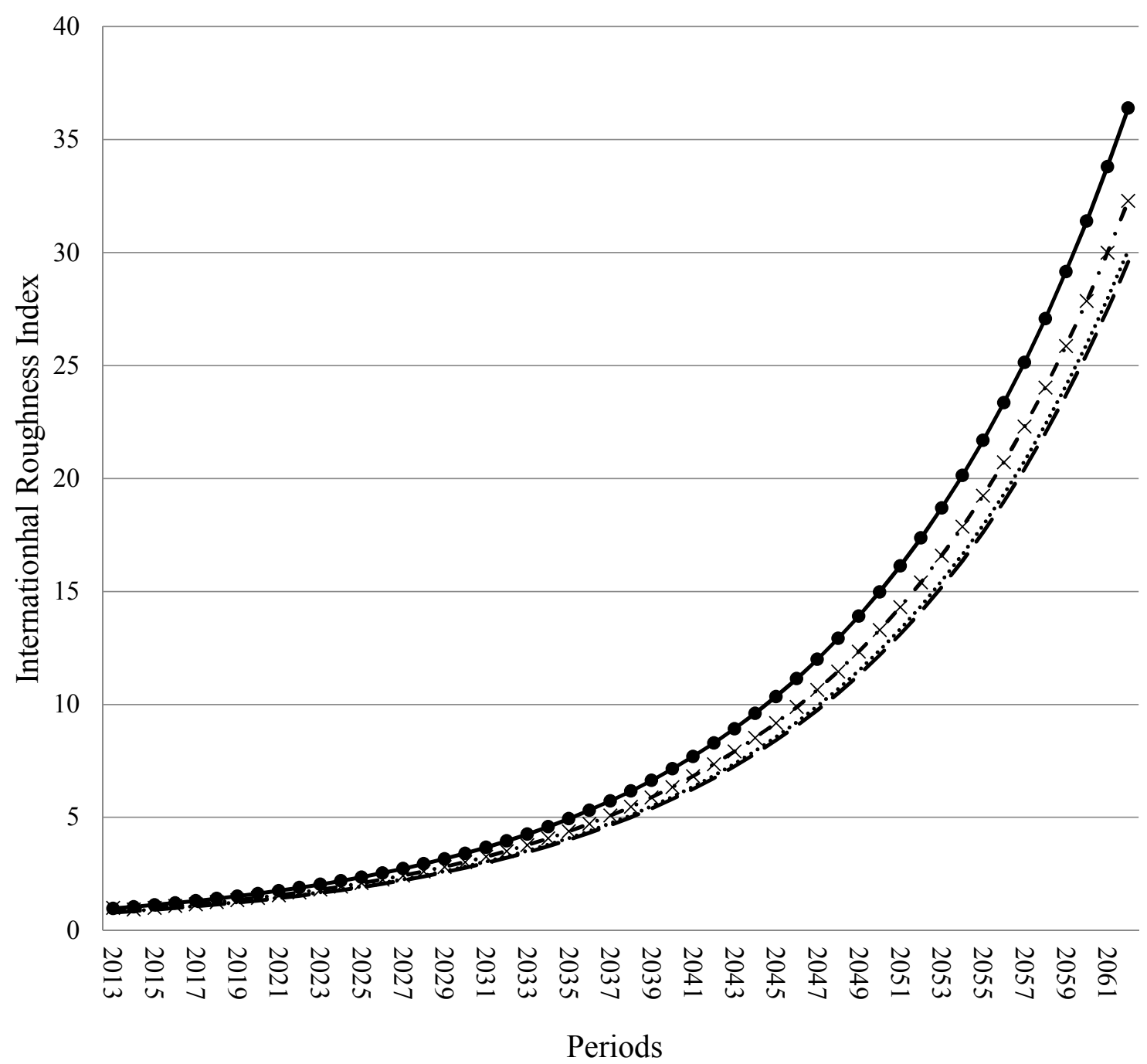

- $x$ - Flexible Arterial $\rightarrow$ Rigid Arterial …….. Flexible Local - Rigid Local 
Table 1: Comparative evaluation of different land use and transportation modeling

\begin{tabular}{|c|c|c|c|c|c|c|c|c|c|c|c|c|c|c|c|c|c|c|c|c|}
\hline Criteria & $\stackrel{\varrho}{\varrho}$ & 岌 & $\frac{Z}{4}$ & 岂 & $\begin{array}{l}\mathbb{W} \\
\text { S } \\
\stackrel{\Sigma}{\Sigma}\end{array}$ & 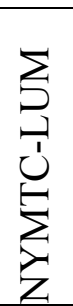 & 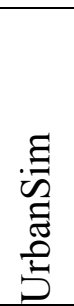 & 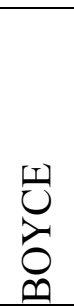 & 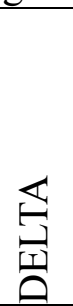 & $\sum_{i}^{-1}$ & 食 & $\underset{\Xi}{\underline{Z}}$ & 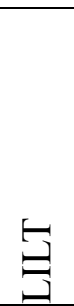 & 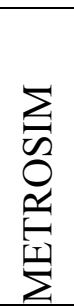 & 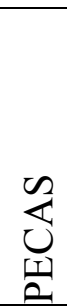 & $\frac{n}{3}$ & 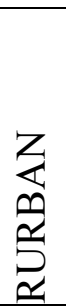 & 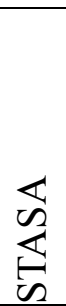 & 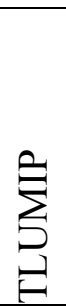 & 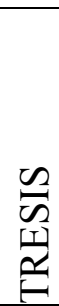 \\
\hline Widely practiced ILUT models & $\mathrm{X}$ & & $\mathrm{X}$ & $\mathrm{X}$ & $\mathrm{X}$ & $\mathrm{X}$ & $\mathrm{X}$ & & & & & & & & & & & & & \\
\hline Inclusion of urban subsystems & $\mathrm{X}$ & $\mathrm{X}$ & $\mathrm{X}$ & $\mathrm{X}$ & & & & & & & & & & & $\mathrm{X}$ & & & $\mathrm{X}$ & $\mathrm{X}$ & \\
\hline In-built transport modeling & $\mathrm{X}$ & $\mathrm{X}$ & $\mathrm{X}$ & $\mathrm{X}$ & & $\mathrm{X}$ & & $\mathrm{X}$ & & $\mathrm{X}$ & $\mathrm{X}$ & $\mathrm{X}$ & $\mathrm{X}$ & $\mathrm{X}$ & $\mathrm{X}$ & & & $\mathrm{X}$ & $\mathrm{X}$ & $\mathrm{X}$ \\
\hline $\begin{array}{l}\text { Simulate demographic change and } \\
\text { household formation }\end{array}$ & & $\mathrm{X}$ & & & & & $\mathrm{X}$ & & $\mathrm{X}$ & & $\mathrm{X}$ & & $\mathrm{X}$ & & & & & & & \\
\hline Static Equilibrium model & $\mathrm{X}$ & & $\mathrm{X}$ & $\mathrm{X}$ & $\mathrm{X}$ & $\mathrm{X}$ & & & & & & & & & & & & & & \\
\hline $\begin{array}{l}\text { Equilibrium model of transport \& } \\
\text { location with endogenous land } \\
\text { prices }\end{array}$ & & & & & & & & & & & & $\mathrm{X}$ & & $\mathrm{X}$ & & & & & & \\
\hline Equilibrium model of transport only & & $\mathrm{X}$ & & & & +7 & $\bar{P}$ & 8 & & & $\mathrm{X}$ & & & & & & & & $\mathrm{X}$ & \\
\hline $\begin{array}{l}\text { Equilibrium model of transport and } \\
\text { activity location separately }\end{array}$ & $\mathrm{X}$ & & $\mathrm{X}$ & $\mathrm{X}$ & & & 8 & & & $\mathrm{X}$ & & & & & $\mathrm{X}$ & & & & & $\mathrm{X}$ \\
\hline $\begin{array}{l}\text { Equilibrium model of transport \& } \\
\text { location } \\
\text { endogenous land prices }\end{array}$ & & & & & & & & $\mathrm{X}$ & & & & & $\mathrm{X}$ & & & & & & & \\
\hline $\begin{array}{l}\text { Equilibrium model of transport \& } \\
\text { location with activities as destination } \\
\text { of trips }\end{array}$ & $\mathrm{X}$ & & $\mathrm{X}$ & $\mathrm{X}$ & & & & $\mathrm{X}$ & & $\mathrm{X}$ & & $\mathrm{X}$ & $\mathrm{X}$ & $\mathrm{X}$ & $\mathrm{X}$ & & $\bar{X}$ & & & \\
\hline Disequilibrium model & & & & & & & $\mathrm{X}$ & & & & & & & & & & & & & \\
\hline $\begin{array}{l}\text { Trip assignment approach for route } \\
\text { choice dispersion }\end{array}$ & $\mathrm{X}$ & & $\mathrm{X}$ & $\mathrm{X}$ & & & & & & & & & & & & & & $\mathrm{X}$ & & \\
\hline $\begin{array}{l}\text { Spatial input-output Coefficients or } \\
\text { demand functions for good flows }\end{array}$ & & & $\mathrm{X}$ & $\mathrm{X}$ & & & & & $\mathrm{X}$ & & & $\mathrm{X}$ & & & $\mathrm{X}$ & & & & & \\
\hline $\begin{array}{l}\text { Industries and households as } \\
\text { consuming and producing factors }\end{array}$ & & & $\mathrm{X}$ & $\mathrm{X}$ & & & & & & & & & & & $\mathrm{X}$ & & & & & \\
\hline
\end{tabular}




\begin{tabular}{|l|l|l|l|l|l|l|l|l|l|l|l|l|l|l|l|l|l|l|l|l|}
\hline Large zone-based model & $\mathrm{X}$ & & $\mathrm{X}$ & $\mathrm{X}$ & $\mathrm{X}$ & & & & & & & & & & $\mathrm{X}$ & & $\mathrm{X}$ & $\mathrm{X}$ & & $\mathrm{X}$ \\
\hline Small zone-based model & & $\mathrm{X}$ & & & & $\mathrm{X}$ & & $\mathrm{X}$ & & & $\mathrm{X}$ & & $\mathrm{X}$ & $\mathrm{X}$ & & & & & $\mathrm{X}$ & \\
\hline Disaggregate or household level & & & & & & & $\mathrm{X}$ & & & & & & & & $\mathrm{X}$ & & & & & \\
\hline
\end{tabular}


Table 2: Exogenous and induced production $\left(E_{i}^{n, t}\right.$, CAD million) of different sectors in the year 2013

\begin{tabular}{|l|r|r|r|r|r|}
\hline Provinces & Production & Consumption & Investment & Govt. spending & Net export \\
\hline New Brunswick & 31484.767 & 12976.3 & 6908.00503 & 27305.78839 & -2391.48 \\
\hline Nova scotia & 38670.777 & 14854.3 & 7824.5819 & 25515.485 & -6410.03 \\
\hline Newfoundland & 40334.352 & 9019 & 14307.5724 & 15959.63232 & 9999.015 \\
\hline Quebec & 359616.28 & 114641.8 & 85044.4286 & 177982.1027 & -29837.5 \\
\hline Prince Edward Island & 5703.4962 & 2352.8 & 1315.32697 & 5447.2825 & -788.144 \\
\hline
\end{tabular}


Table 3: Demand function $\left(P D_{i}^{m n}\right)$ in the year 2013

\begin{tabular}{|c|c|c|c|c|c|}
\hline & Production & Consumption & Investment & $\begin{array}{l}\text { Government } \\
\text { spending }\end{array}$ & $\begin{array}{l}\text { Net } \\
\text { export }\end{array}$ \\
\hline Production & & 0.396 & 0.344 & 0.901 & 0.242 \\
\hline Consumption & 4.325 & & 1.495 & 2.261 & 1.104 \\
\hline Investment & 4.762 & 1.729 & & 3.703 & 0.668 \\
\hline Government spending & 2.394 & 0.629 & 0.829 & & 0.625 \\
\hline Net export & 3.502 & 0.714 & 1.304 & 1.236 & \\
\hline
\end{tabular}


Table 4: Estimated effects of explanatory variables on trips per household during peak and off-peak hours

\begin{tabular}{|c|c|c|c|c|c|c|c|c|}
\hline Time & Purpose & Variables & Coefficients & Standard Error & t Stat & $\mathrm{P}$-value & \multicolumn{2}{|c|}{$95 \%$ confidence interval } \\
\hline \multirow{12}{*}{$\begin{array}{l}\text { Peak- } \\
\text { hour }\end{array}$} & \multirow[b]{4}{*}{ Working } & Intercept & 1.082 & 0.044 & 24.678 & 0.000 & 0.996 & 1.168 \\
\hline & & Auto ownership & -0.023 & 0.008 & -2.969 & 0.003 & -0.039 & -0.008 \\
\hline & & Persons per household & 0.053 & 0.007 & 7.909 & 0.000 & 0.040 & 0.066 \\
\hline & & Occupation & 0.005 & 0.030 & 0.171 & 0.865 & -0.054 & 0.064 \\
\hline & \multirow[b]{4}{*}{ Business } & Intercept & 1.934 & 0.304 & 6.360 & 0.000 & 1.335 & 2.534 \\
\hline & & Auto ownership & -0.074 & 0.092 & -0.800 & 0.424 & -0.256 & 0.108 \\
\hline & & Persons per household & 0.130 & 0.062 & 2.116 & 0.035 & 0.009 & 0.251 \\
\hline & & Occupation & 0.265 & 0.063 & 4.198 & 0.000 & 0.389 & 0.141 \\
\hline & \multirow[b]{4}{*}{ Education } & Intercept & 1.924 & 0.154 & 12.505 & 0.000 & 1.622 & 2.225 \\
\hline & & Auto ownership & -0.011 & 0.005 & -2.084 & 0.037 & -0.021 & -0.001 \\
\hline & & Persons per household & -0.010 & 0.004 & -2.200 & 0.028 & -0.018 & -0.001 \\
\hline & & Occupation & -0.265 & 0.051 & -5.180 & 0.000 & -0.365 & -0.165 \\
\hline \multirow{12}{*}{$\begin{array}{l}\text { Off-peak } \\
\text { hour }\end{array}$} & \multirow[b]{4}{*}{ Working } & Intercept & 1.118 & 0.092 & 12.208 & 0.000 & 0.939 & 1.298 \\
\hline & & Auto ownership & -0.009 & 0.016 & -0.562 & 0.574 & -0.039 & 0.022 \\
\hline & & Persons per household & 0.019 & 0.013 & 1.436 & 0.151 & -0.007 & 0.044 \\
\hline & & Occupation & 0.188 & 0.064 & 2.930 & 0.003 & 0.062 & 0.313 \\
\hline & \multirow[b]{4}{*}{ Business } & Intercept & 2.078 & 0.337 & 6.163 & 0.000 & 1.414 & 2.743 \\
\hline & & Auto ownership & -0.100 & 0.073 & -1.369 & 0.172 & -0.243 & 0.044 \\
\hline & & Persons per household & 0.123 & 0.062 & 1.994 & 0.047 & 0.001 & 0.245 \\
\hline & & Occupation & 0.109 & 0.090 & 1.208 & 0.228 & 0.286 & 0.069 \\
\hline & \multirow[b]{4}{*}{ Education } & Intercept & 2.821 & 0.591 & 4.778 & 0.000 & 1.662 & 3.981 \\
\hline & & Auto ownership & -0.023 & 0.035 & -0.638 & 0.524 & -0.092 & 0.047 \\
\hline & & Persons per household & -0.007 & 0.030 & -0.228 & 0.820 & -0.066 & 0.052 \\
\hline & & Occupation & -0.490 & 0.196 & -2.501 & 0.013 & -0.875 & -0.105 \\
\hline
\end{tabular}


Table 5: Estimated utility function of choosing different modes

\begin{tabular}{|c|c|c|c|c|c|c|c|}
\hline Mode & Variables & Coefficient & $\begin{array}{l}\text { Standard } \\
\text { error }\end{array}$ & $\mathrm{Z}$ & $\mathrm{P}>|Z|$ & \multicolumn{2}{|c|}{$\begin{array}{l}95 \% \text { Confidence } \\
\text { Interval }\end{array}$} \\
\hline \multirow{3}{*}{$\begin{array}{l}\text { Car } \\
\text { driving } \\
\text { alone }\end{array}$} & Constant & -0.685 & 0.010 & -69.58 & 0.000 & -0.704 & -0.666 \\
\hline & Travel time (min) & -0.008 & 0.001 & -12.19 & 0.000 & -0.009 & -0.007 \\
\hline & Travel cost $(\$)$ & -0.095 & 0.008 & -12.42 & 0.000 & -0.080 & -0.110 \\
\hline \multirow{3}{*}{$\begin{array}{l}\text { Car } \\
\text { share }\end{array}$} & Constant & -1.062 & 0.017 & -62.72 & 0.000 & -1.096 & -1.029 \\
\hline & Travel time (min) & 0.025 & 0.002 & 15.93 & 0.000 & 0.022 & 0.028 \\
\hline & Travel cost $(\$)$ & -1.016 & 0.025 & -41.34 & 0.000 & -1.064 & -0.967 \\
\hline \multirow[t]{3}{*}{ Bus } & Constant & -2.451 & 0.017 & -143.96 & 0.000 & -2.485 & -2.418 \\
\hline & Travel time (min) & -0.004 & 0.001 & -5.37 & 0.000 & -0.006 & -0.003 \\
\hline & Travel cost $(\$)$ & 0.052 & 0.009 & 5.87 & 0.000 & 0.035 & 0.069 \\
\hline \multirow[t]{3}{*}{ Metro } & Constant & -2.983 & 0.023 & -131.98 & 0.000 & -3.028 & -2.939 \\
\hline & Travel time (min) & -0.067 & 0.001 & -50.58 & 0.000 & -0.069 & -0.064 \\
\hline & Travel cost $(\$)$ & 0.776 & 0.015 & 50.73 & 0.000 & 0.746 & 0.806 \\
\hline \multirow[t]{2}{*}{ Bicycle } & Constant & -3.585 & 0.028 & -126.48 & 0.000 & -3.640 & -3.529 \\
\hline & Travel time (min) & -0.0168 & 0.002 & -0.10 & 0.000 & -0.034 & 0.0307 \\
\hline
\end{tabular}


Table 6: Traffic volume on different road segments of Montreal city during 2008 and 2013

\begin{tabular}{|c|c|c|c|c|c|c|c|}
\hline $\begin{array}{l}\text { Road } \\
\text { Hierarchy }\end{array}$ & $\begin{array}{l}\text { Pavement } \\
\text { type }\end{array}$ & $\begin{array}{l}\text { Percentile } \\
\text { distribution }\end{array}$ & $\begin{array}{l}\text { Length } \\
\text { (meter) }\end{array}$ & $\begin{array}{l}\text { Travel time } \\
(\mathrm{min}) 2008\end{array}$ & $\begin{array}{l}\text { AADT } \\
2008 \\
\end{array}$ & $\begin{array}{l}\text { AADTT } \\
2008 \\
\end{array}$ & $\begin{array}{l}\text { AADT } \\
\text { growth } \\
2008- \\
2013(\%)\end{array}$ \\
\hline \multirow{8}{*}{ Arterial } & \multirow[t]{4}{*}{ Flexible } & $25^{\text {th }}$ & 14.39 & 0.02 & 7578 & 5304 & 5 \\
\hline & & $50^{\text {th }}$ & 76.76 & 0.07 & 11100 & 7770 & 6.8 \\
\hline & & $75^{\text {th }}$ & 167.13 & 0.18 & 17251 & 12076 & 8.5 \\
\hline & & $99^{\text {th }}$ & 683.46 & 0.67 & 65000 & 45500 & 12.43 \\
\hline & \multirow[t]{4}{*}{ Rigid } & $25^{\text {th }}$ & 15.16 & 0.02 & 7047 & 4933 & 4.5 \\
\hline & & $50^{\text {th }}$ & 85.57 & 0.10 & 9758 & 6831 & 6 \\
\hline & & $75^{\text {th }}$ & 180.45 & 0.21 & 15927 & 11149 & 7.9 \\
\hline & & $99^{\text {th }}$ & 560.14 & 0.63 & 65000 & 45500 & 10 \\
\hline \multirow{8}{*}{ Local } & \multirow[t]{4}{*}{ Flexible } & $25^{\text {th }}$ & 68.67 & 0.08 & 8550 & 2565 & 4 \\
\hline & & $50^{\text {th }}$ & 84.10 & 0.10 & 11702 & 3511 & 5.8 \\
\hline & & $75^{\text {th }}$ & 169.03 & 0.20 & 14723 & 4417 & 7.5 \\
\hline & & $99^{\text {th }}$ & 445.47 & 0.62 & 23000 & 6900 & 12 \\
\hline & \multirow[t]{4}{*}{ Rigid } & $25^{\text {th }}$ & 71.35 & 0.08 & 6030 & 1809 & 3.25 \\
\hline & & $50^{\text {th }}$ & 89.00 & 0.11 & 8378 & 2513 & 5.2 \\
\hline & & $75^{\text {th }}$ & 174.14 & 0.21 & 11999 & 3600 & 6.9 \\
\hline & & $99^{\text {th }}$ & 476.19 & 0.84 & 23000 & 6900 & 9.28 \\
\hline
\end{tabular}




\section{List of Figure Captions}

Figure 1: Flow chart of methodology

Figure 2. Total demand and production of goods and services in Atlantic Provinces of Canada Figure 3: Equivalent Single Axle Loads (ESALs) on regional road networks

Figure 4: Simulated origin-destination map of traffic flow in 2013

Figure 5: Equivalent Single Axle Loads (ESALs) on urban road network of Montreal city Figure 6: International Roughness Index for regional road network of Atlantic Provinces of Canada during 2013-2062

Figure 7: International Roughness Index of road network of Montreal city during 2013-2062 Figure 8: International Roughness Index for regional road network of Atlantic Provinces of Canada during 2013-2062 without simulated traffic

Figure 9: International Roughness Index of road network of Montreal city during 2013-2062 without simulated traffic 